\title{
Hybrid organosilica membranes and processes: Status and outlook
}

I. Agirre (Engineering School of Bilbao) P.L. Arias (Engineering School of Bilbao) H.L. Castricum (University of Twente) M. Creatore (Eindhoven University of Technology) J.E. ten Elshof (University of Twente) G.G. Paradis (ECN) P.H.T. Ngamou (Eindhoven University of Technology) H.M. van Veen (ECN) J.F. Vente (ECN)

February 2014 ECN-W--14-001 


\title{
Hybrid organosilica membranes and processes: Status and outlook
}

\author{
Ion Agirre ${ }^{\mathrm{a}}$, Pedro L. Arias ${ }^{\mathrm{a}}$, Hessel L. Castricum ${ }^{\mathrm{b}, \mathrm{c}, \mathrm{d}}$, Madriana Creatore ${ }^{\mathrm{e}}$, Johan E. ten Elshof ${ }^{\mathrm{b}}$, \\ Goulven G. Paradis ${ }^{\mathrm{d}}$, Patrick H.T. Ngamou ${ }^{\mathrm{e}}$, Henk M. van Veen ${ }^{\mathrm{d}}$, Jaap F. Vente ${ }^{\mathrm{d}, *}$ \\ ${ }^{a}$ Chemical and Environmental Engineering Department, Engineering School of Bilbao (UPV-EHU), Alameda Urquijo s/n, 48013 Bilbao, Spain \\ ${ }^{\mathrm{b}}$ MESA+ Institute for Nanotechnology, University of Twente, P.O. Box 217, 7500 AE Enschede, The Netherlands \\ ${ }^{c}$ Van't Hoff Institute for Molecular Sciences, University of Amsterdam, Science Park 904, 1098 XH Amsterdam, The Netherlands \\ dEnergy research Centre of the Netherlands, P.O. Box 1, 1755 ZG Petten, The Netherlands \\ e Department of Applied Physics, Eindhoven University of Technology, P.O. Box 513, 5600 MB Eindhoven, The Netherlands
}

\section{A R T I C L E I N F O}

\section{Article history:}

Available online 8 August 2013

\section{Keywords:}

Hybrid silica membranes with organic links $\mathrm{HybSi}^{\circledR}$

Gas separation

Pervaporation

Sol-gel technology

Plasma enhanced chemical vapor deposition

\begin{abstract}
A B S T R A C T
In the past, the research in molecular separation membranes prepared through sol-gel technologies has been dominated by ceramic membranes. Especially, silica membranes have been studied in great depth. Steps towards hybrid organosilica membranes were taken by using pendant organic groups. However, only with the appearance of organically bridged silica, stable and reliable membranes that are suitable for large scale industrial utilization have become available. In this paper, we provide an overview of recent development of hybrid silica membranes that contain organic bridges. The freedom of choice in precursor allows for a flexible approach towards tailoring of the membrane properties. New support materials can be used by applying alternative deposition methods, such as expanding thermal plasma chemical vapor deposition. The robustness of the membrane concept allows for the design of novel separation process concepts in which the demonstrated stability is required.
\end{abstract}

(c) 2013 Elsevier B.V. All rights reserved.

\section{Introduction}

Molecular separation membranes are expected to play an important role in reaching the environmental goal to reduce $\mathrm{CO}_{2}$ emissions by approximately $50 \mathrm{Gt}$ per year by 2050 [1]. Membranes can be applied as effective and energy-efficient separation systems to dehydrate wet bio-based fuels [2,3]. Also application in the (petro)chemical industry is widely considered to significantly enhance the energy efficiency of key processes. Although exact numbers are missing, separation processes are known to be one of the more energy-intensive steps in a chemical production plant. Molecular separation membranes can play a crucial role here [4$6]$.

In this paper, the status and potential of hybrid organosilica membrane materials, and their use in different molecular separations are presented. An outlook is given towards further developments. Pure inorganic silica membranes have a low hydrothermal stability $[7,8]$, reducing the application window for dehydration of organic liquids by pervaporation to temperatures not exceeding $\sim 75{ }^{\circ} \mathrm{C}$ [9]. The incorporation of methyl groups

* Corresponding author at: ECN, Westerduinweg 3, P.O. Box 1, 1755 ZG, 1755 LE Petten, The Netherlands. Tel.: +31 8851549 16, fax: +31 885158615 .

E-mail address: vente@ecn.nl (J.F. Vente).

URL: http://www.ecn.nl (J.F. Vente).
[10] in the silica structure allows an increase of the application temperature to $95{ }^{\circ} \mathrm{C}[9]$. This results in an application window with a temperature range that is similar to that of polymeric membranes like PVA [11] and polyimides [12]. Ceramic membranes will only have a value in the market when clear advantages over the commercially produced polymeric ones can be obtained. These advantages may include a higher performance, i.e. a higher selectivity and permeance, and an increased stability. As a result the application window can be broader than the more commonly used polymeric membranes. Envisaged application extensions are a higher application temperature, higher chemical stability towards strong organic solvents, acids and water, and a smaller sensitivity to swelling. The increase of operation periods under a wider range of applications will result in a positive business case for all industrial parties involved.

The focus of this review will be the preparation of membranes bridged polysilsesquioxanes precursors and their application in processes. Other types of hybrid membranes are reviewed elsewhere [13]. These current class of materials is characterized by covalent bonds between both oxygen and hydrocarbons to silicon. These materials are prepared by sol-gel processing [14] of monomers that contain an organic group that bridges typically two functional silyl groups [15]. A great variety of organic bridges can be used, including aromatic, alkyne, alkene, alkane, and functionalized moieties [16]. A general trend in mesoporous materials is that 
the pore diameter increases with increasing length of the bridge [16-18]. Alternatively, organic templates can be used to direct the pore formation process [19]. The positive impact of the organic bridge on the hydrothermal stability for mesoporous materials has been recognized [20]. The application of similar microporous materials in molecular separation membranes was reported as recently as 2008 [21].

This review paper is structured in a number of chapters. We start with material and preparation considerations, which include structure-property relations. With respect to preparation, our focus is on sol-gel processes, in which bridging and pendant organic groups with various structures are incorporated. This is followed by a generic overview of possible applications of these membranes. While the main focus is on pervaporation, developments in gas separation and nanofiltration are discussed as well. A pervaporation process case study is presented for the production of an acetal, which can be used as a renewable diesel additive. The topics of the last chapters are recent developments in alternative preparation methods, new support options, new processes, and an outlook towards the requirements in fundamental knowledge needed to allow further applicability.

\section{Precursors and preparations}

\subsection{Preparation of oxide membranes}

Oxide microporous materials and membranes are typically prepared by conventional sol-gel approaches [14]. The mild synthesis conditions of sol-gel preparation allow the synthesis and control of nanoporous inorganic materials. Thin layers, $<1 \mu \mathrm{m}$, can be efficiently deposited onto a support by coating with the sol before the transition to the gel phase occurs. The first membranes prepared in this way were made from tetraethylorthosilicate (TEOS) [22-24]. A microporous, pore diameter $d_{\mathrm{p}}<2 \mathrm{~nm}$, structure is formed upon acid-catalyzed hydrolysis and condensation of TEOS in mixtures with ethanol, water and nitric or hydrochloric acid The basic degrees of freedom are the relative amounts of the four chemicals involved, the reaction temperature and time $[14,25,26]$. Variation in the preparative conditions leads to a great variety of membrane properties, which can be further enlarged through the use of pore forming agents [27]. The silica membranes can be doped with transition metal cations by the addition of a suitable alkoxy-functionalized metal precursor during sol preparation. Examples include Fe [28], Co [29], Zr [30], and $\mathrm{Nb}[31,32]$. Inorganic membranes that consist completely of $\mathrm{TiO}_{2}$ and $\mathrm{ZrO}_{2}$ have also been prepared [33-36], although their dense atomic packing generally leads to low permeabilities [37]. The sol preparation part is followed by a coating step onto a multilayer support system. The most widely applied support system consists of a layer of mesoporous $\gamma-\mathrm{Al}_{2} \mathrm{O}_{3}$ [38], which in turn is supported by macroporous $\alpha-\mathrm{Al}_{2} \mathrm{O}_{3}$ [39]. After drying, the membrane preparation is concluded by calcination of the coated membrane.

\subsection{Precursor choice for hybrid organosilica}

The first membranes which did contain organic fragments were prepared by introducing alkyl-terminating groups into an otherwise inorganic membrane. Membranes have been made through the co-condensation of TEOS with mono-substituted R-trialkoxysilane precursors, with $\mathrm{R}=$ alkyl [9,40], phenyl [41], fluorinesubstituted alkyl [42], unsaturated (alkene) [43], and amino groups $[44,45]$. Only recently, a bridging organic moiety was considered for the fabrication of a molecular separation membrane [21]. The precursor used for the preparation of the organically linked silica membranes was 1,2-bis(triethoxysilyl)ethane (BTESE,
$\left.\left(\mathrm{C}_{2} \mathrm{H}_{5} \mathrm{O}\right)_{3}-\mathrm{Si}-\mathrm{C}_{2} \mathrm{H}_{4}-\mathrm{Si}-\left(\mathrm{OC}_{2} \mathrm{H}_{5}\right)_{3},\right)$, which is still the most reported precursor molecule. The materials properties can be controlled by changing the structure of this bridging group [46,47]. Applying the BTESE precursor as a basis, other precursors can be added to modify the surface properties. The inorganic content can be increased by applying mixtures with TEOS [48]. Membranes with a higher organic content have been prepared with additives consisting of R-alkoxysilianes with $\mathrm{R}$ an alkyl $[21,49]$ or amino side group [50]. The addition of $\mathrm{Nb}$ has led to a decreased permeance of $\mathrm{CO}_{2}$ in $\mathrm{SiO}_{2}$ - based membranes and an increased selectivity towards hydrogen [31]. This has inspired the addition of this precursor to BTESE-based membranes [51,52].

Organosilica precursors can also be used to synthesize inorganic silica membranes. Organic side groups $[53,54]$ or bridging organic groups $[27,55]$ are subsequently deliberately pyrolysed by hightemperature calcination. The organic groups thus served as pore formers and did not remain in the structure. This procedure is not further described in this review.

\subsection{Sol preparation and coating}

Control over the pore size distribution and defect concentration is essential in obtaining a high quality membrane [39]. Microporous and defect-free silica-based membranes with molecular sieving properties require acid-catalyzed hydrolysis and condensation, i.e. preparation conditions below the isoelectric point [14]. The reaction rate is determined by the temperature, the concentration of the reactants, the silsesquioxane precursor and water, and of the acid catalyst in the solvent. Condensation reactions lead to the formation of oligomeric colloidal structures and ultimately to the formation of a continuous network gel with high viscosity. NMR studies showed that BTESE hydrolyzes more rapidly than TEOS while condensation rates are of the same order [56]. The larger size and larger network-forming ability of BTESE, however, result in much faster colloidal growth than for TEOS. As thin-film coating requires low sol viscosity, lower reactant concentrations must be applied for BTESE than for TEOS [46,57].

The mean colloid hydrodynamic diameter can be applied as a measure for the suitability of a sol for membrane coating. A straightforward assessment can be done with dynamic light scattering [58]. A lower limit is set by the pore size of the mesoporous support layer, around $4 \mathrm{~nm}$ for $\gamma-\mathrm{Al}_{2} \mathrm{O}_{3}$, to prevent extensive infiltration of the sol into the substrate. At a particle size larger than $15 \mathrm{~nm}$, growth is governed by colloid-colloid aggregation rather than the reaction of monomer species with colloids. Interaction between two large colloids for further-developed sols leads to broad colloid size distributions and viscous sols unsuitable for applying coatings [46].

Sol synthesis is usually carried out at $333 \mathrm{~K}$ or higher, with reaction times of several hours. An effective way to quench the reaction is to cool to room temperature and dilute the colloidal sol prior to coating. In this way, a stable sol is obtained with very limited ongoing condensation that can be handled easily. It can be used for coating during several hours, although the individual coating procedure does not take more than minutes. The coating procedure itself is preferably performed in a clean environment [40] to reduce the influence of the presence of dust particles which can adhere to the drying surface and create defects.

\subsection{Calcination}

The preparation of the membrane is finalized with a thermal treatment to consolidate the materials. The organic groups can be retained in the structure by applying mild thermal conditions, with temperatures between 250 and $300{ }^{\circ} \mathrm{C}$ and slow heating and cooling rates $(0.5-1 \mathrm{~K} / \mathrm{min})$, in an inert atmosphere, usually 
nitrogen [21]. A lower temperature tends to result in functional membranes with lower selectivities and permeances in both pervaporation and gas separation tests [59]. The calcination step can be replaced by a $\mathrm{HCl}$ assisted densification using the vapor originated from an 35\% aqueous $\mathrm{HCl}$ solution [60].

For gas separations, optimal calcination temperatures as high as $450{ }^{\circ} \mathrm{C}$ have been reported [51]. This temperature is very close to the clear onset of partial pyrolysis at $470^{\circ} \mathrm{C}$ where the appearance of the materials changes from light to dark and TGA-MS reveals the loss of organic groups $[21,61]$. In air, the decomposition temperature is reduced to a value in the range from $280^{\circ} \mathrm{C}[55]$ to $315^{\circ} \mathrm{C}$ [21]. Aryl bridges have been reported to be removed from the system at a temperature between 400 and $500{ }^{\circ} \mathrm{C}$ [27]. Finally, covalently attached organic templates have been reported to be fully oxidized at $350^{\circ} \mathrm{C}$ [53]. FTIR analyses showed a significantly reduced amount of $\mathrm{Si}-\mathrm{C}$ and $\mathrm{C}-\mathrm{H}$ groups after calcination at $450{ }^{\circ} \mathrm{C}$ under nitrogen [52]. The steam stability was found to be reduced [62]. Despite all these data, knowledge of the influence of the calcination temperature and atmosphere on the reactivity of the bridging organic group is still minimal. Indications have been found that under low temperature plasma conditions the bridging groups are less stable than the terminating groups [63]. The extrapolation of these findings to temperatures above $300{ }^{\circ} \mathrm{C}$ is not straightforward and it cannot be ruled out that the organic bridges dissociate into two terminating groups without weight loss at a temperature lower than the onset of pyrolysis.

\section{Organosilica membranes in liquid and gas separations}

\subsection{Pervaporation applications}

The HybSi ${ }^{\circledR}$ membrane was originally developed for pervaporation applications, and not surprisingly most application-oriented papers focus on the separation of water from organic solvents. In this section, we present the technical application window with special attention to the long-term behavior.

In the publication of 2008 [21], a long term continuous pervaporation experiment at $150^{\circ} \mathrm{C}$ was reported for the first time. Data for a period of over 500 days were reported, without any indication of reduced permeate purity in the separation of water from $n$-butanol. An even longer continuous testing period of 1000 days was presented in 2011 [64] (Fig. 1). Although over the full period of time the permeate water purity remains constant at a value of over $96 \mathrm{wt} . \%$ for a feed containing $5 \mathrm{wt} . \%$ of water in n-BuOH, a flux decline is observed during the first 400 days. In practical applications, this can be overcome by gradually and slightly increasing the operation temperature over the full life time of the membrane. The separation factor of a membrane based on a mixture of BTESE and

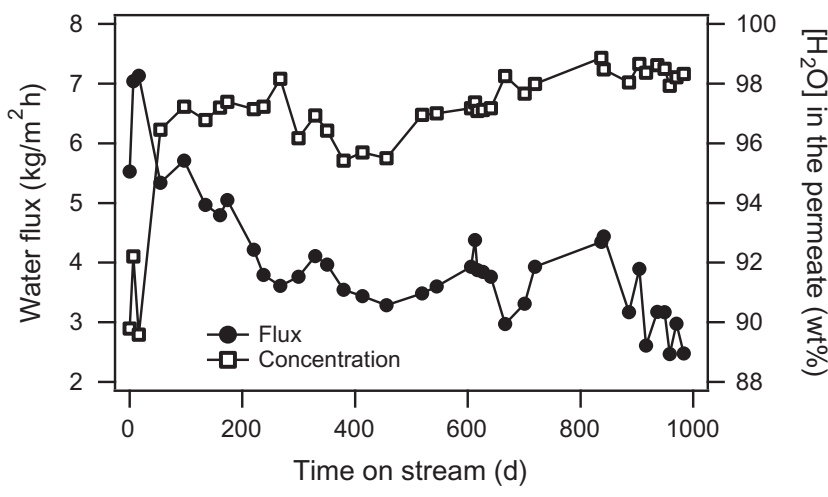

Fig. 1. Separation performance (water flux and water content in the permeate) for the dehydration of 3 wt.\% water from $n$-butanol at $150{ }^{\circ} \mathrm{C}$ [64].
MTES, is lower than that based on pure BTESE, while membranes based on pure BTESM can have the highest separation factor (Table 1) [47]. In this way, the permeate purity can be increased to over 99.5 wt.\% in the dehydration of 5 wt.\% water in $n$-butanol. The BTESM membrane is even selective in the dehydration of methanol with a separation factor of over 20 .

The addition of MTES to TEOS-based membranes resulted in a substantial increase of the hydrothermal stability $[9,10]$. The reduction of the separation factor was explained by a bimodal pore size distribution in which also pores of $\sim 2 \mathrm{~nm}$ are present [65]. With respect to the hydrothermal stability in pervaporation, the addition of MTES cannot be considered to be of additional value compared to membranes from pure BTESE. In fact, an almost twice faster decline of the flux was observed in the presence of methyl groups [57].

The resistance against more aggressive solvents has been gauged using e.g. the aprotic n-methyl pyrrolidone, NMP, one of strongest solvents in its class and for that reason frequently used in polymer manufacturing. A stable performance was reported during the 50 days of measurement [64]. For the acetal production described below, the long-term performance under the relevant conditions has been tested in the presence of an ethanol - butyraldehyde - 1,1 diethoxybutane -water mixture [66]. Also under these conditions no membrane performance decline was observed.

The influence of the presence of an organic, acetic, acid and an inorganic, nitric, acid has been studied as well. First $1.5 \mathrm{wt} . \%$ of acetic acid was added to a mixture of $5 \mathrm{wt} . \%$ water in ethanol [47], later this amount of acid was increased to 15 wt.\% [64]. Under these conditions, only a very limited selectivity decline was observed during the whole measurement period, which ranged from 50 to 350 days. The dehydration of acetic acid has been studied in the past for purely ceramic membranes [67] and indications were found that it could be feasible for BTESE-based membranes [68] in experiments that lasted in the order of days. Long term stability under the relevant operation conditions remains to be demonstrated. Limitations in acid resistance of the $\mathrm{HybSi}^{\circledR}$ membrane became apparent when the concentration of $\mathrm{HNO}_{3}$ is increased to $0.50 \mathrm{wt} . \%$ in a mixture with $5 \mathrm{wt} . \%$ water and butanol [69]. A slow but steady decline in permeate purity from $>99 \%$ to $~ 95 \%$ occurred over a 30-day period. A faster loss of the selectivity, within hours, was found after the addition of $1 \mathrm{wt} . \%$ methanesulfonic acid [64]. Post-test analysis showed that both the selective layer and the $\gamma$ $\mathrm{Al}_{2} \mathrm{O}_{3}$ sub-layer had disappeared.

The discussion above focused on the removal of water from various organic solvents. For these membranes water was the fastest permeating species. However, the properties of the membrane can be tailored towards organic selectivity through the use of alternative precursors $[46,49]$. Especially, the combination of bridging and terminating hydrocarbon moieties leads to promising results. Fig. 2 shows that a BTESE - RTES-based $(\mathrm{R}=$ alkyl $)$ membrane changes from preferentially water permeating to butanol permeating when the number of carbon atoms in the organic tail increases to 10 . This has been explained by an increased water contact angle or stronger hydrophobicity (Fig. 3). A high $n$-butanol flux was also

Table 1

Separation performance of the three types of hybrid silica membranes for dehydration of alcohol/water (95/5 wt.\%) mixtures [47].

\begin{tabular}{llllll}
\hline Alcohol & $\mathrm{T}$ & $J_{\mathrm{H} 2 \mathrm{O}}$ & \multicolumn{2}{l}{ wt.\% $\mathrm{H}_{2} \mathrm{O}$ in permeate } \\
\cline { 5 - 6 } & ${ }^{\circ} \mathrm{C}$ & $\mathrm{kg} \mathrm{m}^{-2} \mathrm{~h}^{-1}$ & BTESE/MTES & BTESE & BTESM \\
\hline$n$ - $\mathrm{BuOH}$ & 95 & $2.0-3.6$ & 95.8 & 99.6 & 99.8 \\
$n-\mathrm{PrOH}$ & 85 & $1.5-2.8$ & 83.5 & 99.5 & 99.5 \\
$\mathrm{EtOH}$ & 70 & $0.8-1.5$ & 42.0 & 89.2 & 92.2 \\
$\mathrm{MeOH}$ & 55 & $0.3-0.6$ & 4.6 & 18.6 & 55.1 \\
\hline
\end{tabular}




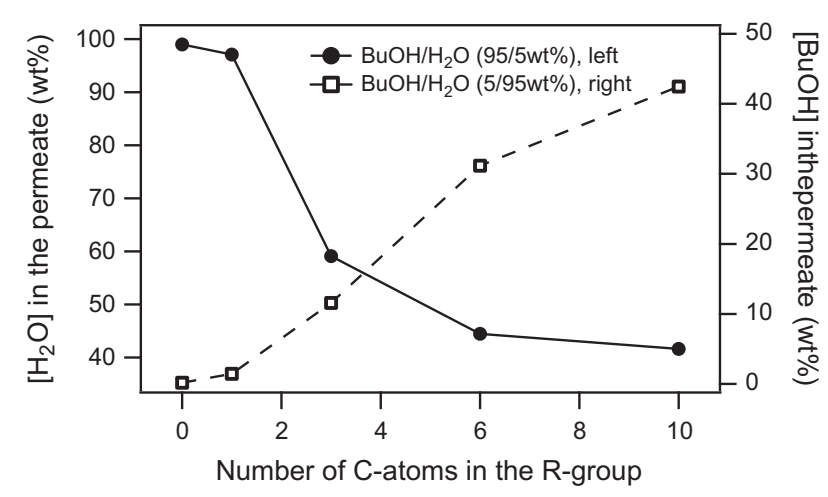

Fig. 2. Permeate concentration as a function of the number of $C$ atoms in the terminating R-group added to BTESE in pervaporation experiments for butanol/ water feed mixtures of $95 / 5$ and $5 / 95$ wt.\%. at $95{ }^{\circ} \mathrm{C}$ [49].

observed for octane- or biphenyl-bridged membranes [46]. The hydrophobic character is related to the large size of the organic bridging group. The rigidity of the biphenyl bridges makes this material possibly suitable for the separation of mixtures of larger molecules by pervaporation.

\subsection{Gas separation applications}

A second class of applications is that of gas separations. One of the obvious differences with the separations in the liquid phase is a much smaller density of the feed stream. Industrial relevant gases include $\mathrm{H}_{2}, \mathrm{CO}, \mathrm{CO}_{2}$, and $\mathrm{CH}_{4}$. The size differences between these molecules are in general smaller than in the liquid phase. Furthermore, differences in interaction between these molecules and the membranes are smaller. As a result, it is more difficult to reach high selectivities. While high selectivities can be reached with inorganic silica membranes, e.g. $\mathrm{H}_{2} / \mathrm{CH}_{4}>4000$ [40], the introduction of terminating methyl groups leads to a dramatic decrease [10]. The first results on gas separating properties of organically bridged silica were presented during the Tokyo ICIM conference in 2008 [70]. $\mathrm{A} \mathrm{H}_{2} / \mathrm{N}_{2}$ selectivity between 20 and 30 was found (Fig. 4). These results were later independently reproduced and ascribed to the more open pore structure as compared to that of purely inorganic silica [61,71].

To increase the moderate selectivity, the influence of adding pure inorganic silica to organosilica was studied and found to be limited [48]. However, much higher selectivities were reported when $\mathrm{Nb}$ was added to a BTESE-based matrix [51,52], The increased $\mathrm{H}_{2} / \mathrm{CO}_{2}$ selectivity was ascribed to a number of effects, including the formation of additional acid sites and densification. In comparison with other reports, the optimal calcination temperature is high, $450{ }^{\circ} \mathrm{C}$. The impressive values of $\alpha \mathrm{H} 2 / \mathrm{CO}_{2}$ up to 700 [72] may be related to a very much reduced organic content [52]: FTIR analyses did not reveal the presence of organic moieties.

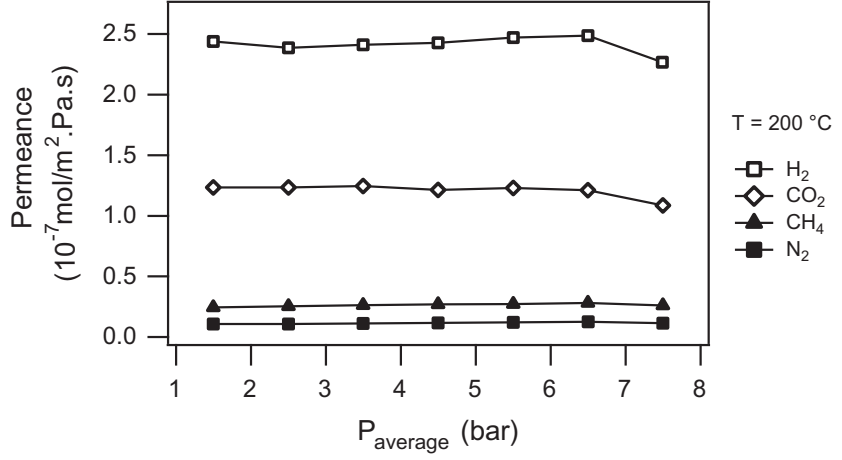

Fig. 4. Permeances vs. average membrane pressure of different pure and single gasses for a BTESE membrane at $200{ }^{\circ} \mathrm{C}$. Single gas selectivity $\mathrm{H}_{2} / \mathrm{N}_{2}=20-30$.

Another way to control the gas separation properties is through variation of the organic bridging group. A series of membranes was prepared with a different size, flexibility, and shape of the organic bridging group. For this study, bis(triethoxysilyl)alkanes $\left(\mathrm{C}_{n} \mathrm{H}_{2 n}\right)$ with $n=1,2$ and 8, -benzene and -biphenyl [46] were selected. To allow optimal comparison of the structural and functional differences related to the organic bridging groups, the colloid size distributions were adjusted to a mean size of $\sim 6 \mathrm{~nm}$. The materials with the shortest, $\mathrm{CH}_{2}$ and $\mathrm{C}_{2} \mathrm{H}_{4}$ alkylene, bridges exhibited the highest $\mathrm{H}_{2} / \mathrm{N}_{2}$ single gas permeance ratios ( 15 at $523 \mathrm{~K}$ ), and are thus most suitable for size-based molecular sieving. The highest $\mathrm{CO}_{2} / \mathrm{H}_{2}$ permeance ratios were observed for octane- and benzene-bridged organosilica ( 1.6 at $323 \mathrm{~K}$ ). As $\mathrm{CO}_{2}$ has a larger diameter than $\mathrm{H}_{2}$, transport through these materials is dominated by the affinity between the hybrid silica materials and $\mathrm{CO}_{2}$ (Fig. 5). The negative apparent activation energy of $\mathrm{CO}_{2}$ through the BTESEbased membrane is consistent with this observation. Considering that the high size selectivity of inorganic silica membranes has resulted in much lower $\mathrm{CO}_{2} / \mathrm{H}_{2}$ ratios [73], the more open structure of hybrid silica materials with large bridging groups is apparently advantageous to enhance affinity-based transport. Both size- and affinity-based transport participate in $\mathrm{CO}_{2} / \mathrm{CH}_{4}$ permeance ratios, which were highest for $\mathrm{CH}_{2}$ and $\mathrm{C}_{2} \mathrm{H}_{4}$ bridges (8-10 at $323 \mathrm{~K}$ ).

The octane-bridged material showed strongly temperaturedependent transport for all investigated gases (Fig. 5). The flexibility of the organic bridge results in a material with a polymeric character, while the network backbone structure of an inorganic ( silica) material is retained. While the applicability of organic polymers is often limited by plasticization, no indication for plasticization was found in either of the hybrid silica materials.

The effect of additional pendant methyl groups was studied in membranes from a 1,1,3,3-tetraethoxy-1,3-dimethyldisiloxane (TEDMDS) precursor [68], employing acetic acid as a catalyst and calcination up to $550^{\circ} \mathrm{C}$. A comparison with hexaethoxydisiloxane (HEDS) shows a larger pore size for membranes from TEDMDS, which was explained by a combination of a larger structural unit and a looser structure as a result of a lower degree of cross-linking.

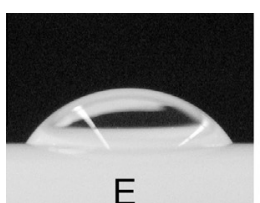

E
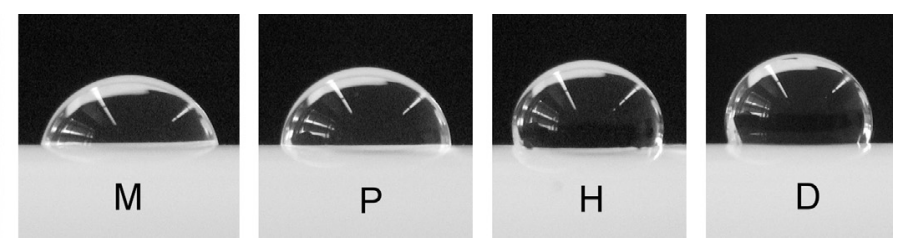

Fig. 3. Photographs of water drops on the surface of the membrane series without terminating alkyl groups (E), and with methyl (M), $n$-propyl (P), $n$-hexyl (H), and $n-$ decyl (D) groups respectively. In the latter cases, one out of three silicon atoms was bound to an alkyl group. A clearly increasing contact angle with increasing alkyl length can be observed [49]. 


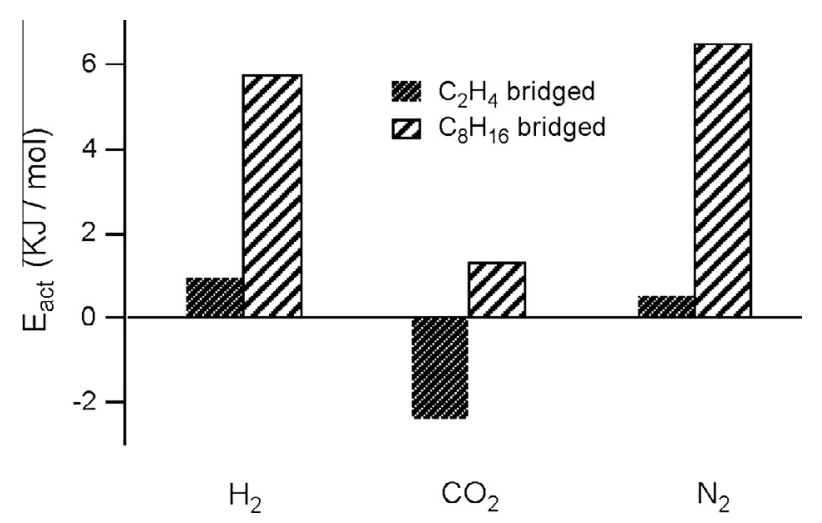

Fig. 5. Apparent activation energies $E_{\mathrm{app}}$ of the permeance of $\mathrm{H}_{2}, \mathrm{CO}_{2}$ and $\mathrm{N}_{2}$ through $\mathrm{C}_{2} \mathrm{H}_{4}$ and $\mathrm{C}_{8} \mathrm{H}_{16}$-bridged organosilica membranes, averaged for feed pressures of 3-9 bar.

The pendant groups may aggregate inside the silica networks during the sol-gel process, and form larger spaces for gas permeation. While the pore size was estimated to be similar to that of BTESE membranes, the $\mathrm{H}_{2}$ permeability of TEDMDS membranes was substantially lower, which is in line with observations on MTES/BTESE mixtures. This shows that the effect of pendant methyl groups on the structure and permeation properties is independent on the synthesis route followed.

Inspired by results obtained by the functionalization of the pure silica with amino containing terminating groups [44,45], the effect on the gas permeation of the addition of three different aminofunctionalized groups to BTESE based membranes was studied [50]. The addition of (3-aminopropyl) triethoxysilane (APTES) shows a decreasing hydrogen permeability with an increasing content of APTES (Fig. 6). This low gas permeability and the contrasting high water fluxes in pervaporation were explained in relation to strong water adsorption. The single gas selectivities and pervaporation separation factors remain essentially unchanged. The results for the other two amino-functionalized terminating groups were comparable.

\section{The production of acetal: a case study}

One of the possible applications that has been suggested for pervaporation membranes is related to the dehydration of reaction mixtures [74]. Till date, membranes have found limited utilization in this field. The breakthrough in stability of the $\mathrm{HybSi}^{\circledR}$ membrane may renew the interest in this topic. The interest in acetals is

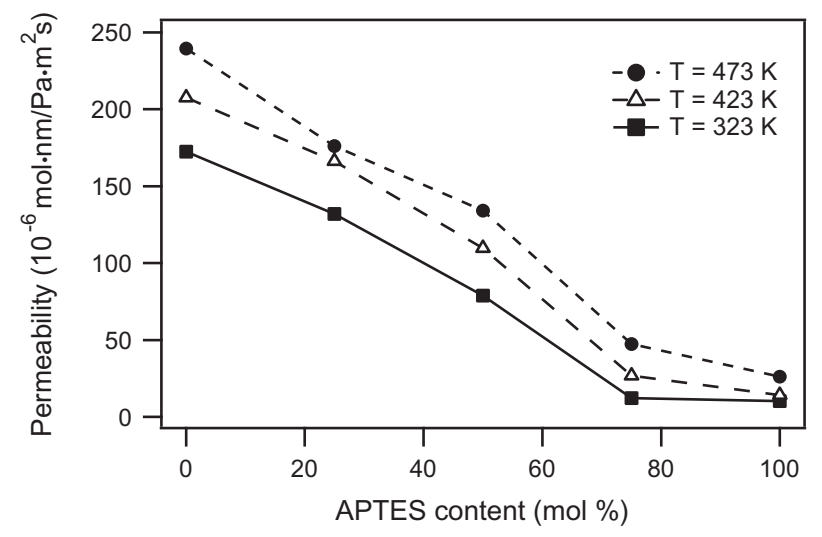

Fig. 6. $\mathrm{H}_{2}$ permeability as a function of concentration of (3-aminopropyl)triethoxysilane (APTES) in the BTESE matrix at 323,423 , and $523 \mathrm{~K}$ [50]. increasing in recent years [75-77]. Acetals can be considered as promising bio-based diesel additives. The production of these compounds, from an alcohol and an aldehyde, suffers from low conversions due to thermodynamic limitations. The reaction under consideration is the acetalization of ethanol and butyraldehyde to produce 1,1-diethoxybutane and water:

$2 \mathrm{C}_{2} \mathrm{H}_{5} \mathrm{OH}+\mathrm{C}_{3} \mathrm{H}_{7} \mathrm{CHO} \leftrightarrow \mathrm{C}_{3} \mathrm{H}_{7} \mathrm{C}\left(\mathrm{OC}_{2} \mathrm{H}_{5}\right)_{2}+\mathrm{H}_{2} \mathrm{O} \Delta H_{r}^{25^{\circ} \mathrm{C}}=-31 \mathrm{~kJ} / \mathrm{mol}$

This reaction presents high thermodynamic limitations, for example using conventional reactors the achieved conversions are around $40 \%$ at $70{ }^{\circ} \mathrm{C}$ [78]. In order to overcome these limitations, any reactor system which allows the removal of water from the mixture will increase the conversion. Reactive distillation systems, for instance, showed a maximum conversion of 50\% [79], while values of $70 \%$ were reached with a membrane reactor using a HybSi ${ }^{\circledR}$ membrane [66]. In all these experiments, the same ionexchange resin, Amberlyst 47, was used as heterogeneous catalyst. To come to an assessment on the most promising technology and configuration, a process comparison performed at a $50 \mathrm{kt} / \mathrm{year}$ scale will be highlighted here.

\subsection{Full scale process comparison}

\subsubsection{Base case}

The base case consists of a 1,1-diethoxybutane production process based on conventional unit operations and is built up from a tubular reactor and distillation (Fig. 7a). The reaction mixture to be separated by distillation is very complex due to its four azeotropes as well as the immiscibility of some of the binary mixtures. The first column (50 equilibrium stages) recycles the non-reacted ethanol and butyraldehyde as well as some of the water. The bottom products, water and 1,1 diethoxy butane, are directed to a decanter giving a pure water and an acetal-water mixture. This latter mixture is distilled in a second column producing pure 1,1 diethoxy butane. As no reactants are lost in the product, the overall conversion is nearly $100 \%$.

\subsubsection{Reactive distillation}

In this case the plug flow reactor of the base case was replaced by a reactive distillation column (Fig. 7b) [79]. Again two additional columns were required to reach the purity demands. The maximum achievable conversion in the reactive distillation unit itself is $50 \%$ [79]. However, as some water is recycled and the reaction temperature is increased the conversion per pass remained essentially constant. Therefore, the downstream separation was largely unchanged from the base case.

\subsubsection{Membrane case}

As initial estimates indicated that an integration of reaction and membrane separation lead to unrealistic values [80], various nonintegrated methods of combining reaction and membrane separation were analyzed:

(1) Reactor followed by pervaporation in series (Fig. 8a),

(2) Reactor and pervaporation with a recycling loop (Fig. 8b),

(3) Reactor followed by pervaporation and distillation with a recycling loop (Fig. 8c).

For a bench scale plant the results of these alternatives are summarized in Table 2 [81]. Case 3, in which pervaporation in combination with a distillation column is used, seems to be the most promising option.

The first estimates for a full scale process indicated that an isothermal membrane module ( $\sim 550 \mathrm{~m}^{2}$ for the $50 \mathrm{kt} / \mathrm{y}$ process $)$ could be more economic than an adiabatic module $\left(1200 \mathrm{~m}^{2}\right)$ in 


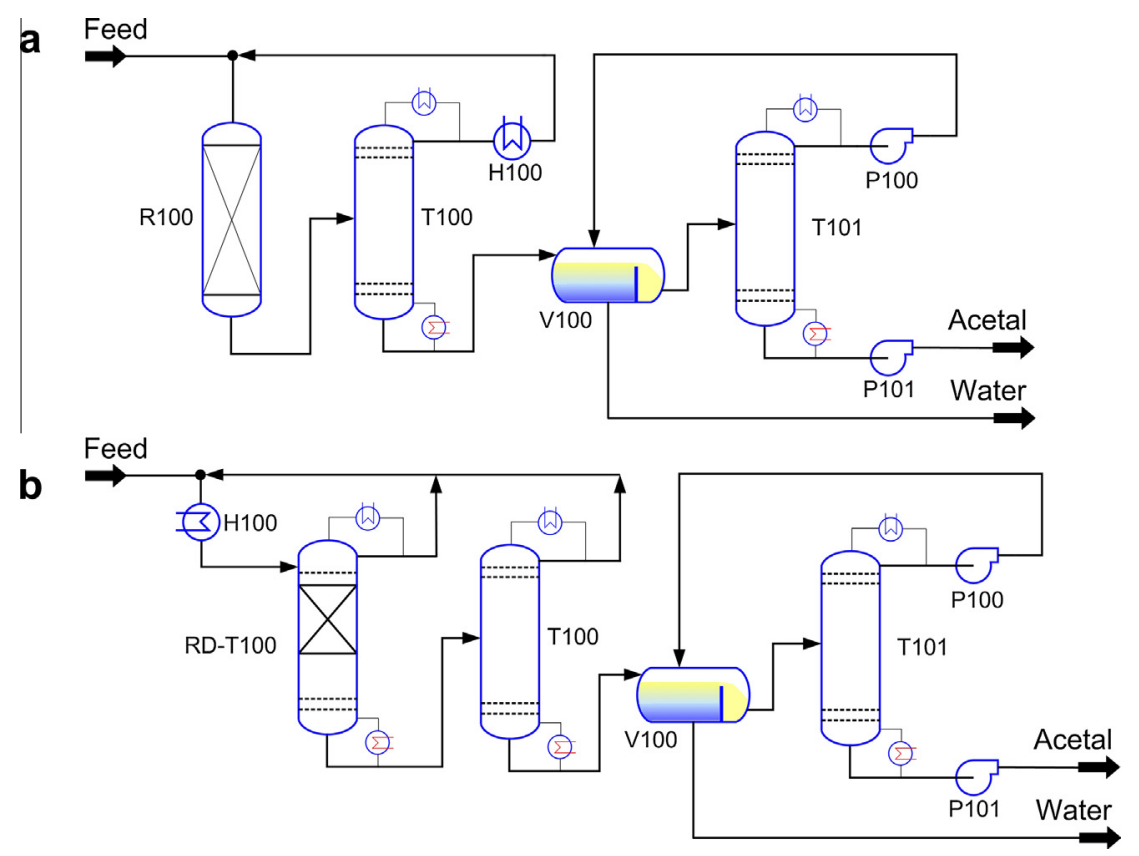

Fig. 7. Base case, (a) and reactive distillation case, (b) flowsheet diagrams [80].

terms of capital, maintenance and membrane replacement costs. This is mostly due to a temperature decrease of $\sim 45^{\circ} \mathrm{C}$ between the inlet and the outlet of an adiabatic pervaporation module, which results in a lower permeance. In all cases the permeate pressure was kept at 5 mbar. For the economics, as some ethanol permeates through the membrane, the costs of a simple distillation column (not included in the figure) which recovers and recycles the ethanol was also considered.

\subsection{Economic comparison}

An economic comparison between the base case, reactive distillation, and the membrane case is presented in Table 3. The total capital costs are the highest for the membrane case, but the utility costs are the lowest because of a higher energy efficiency. Overall, the pervaporation based process configuration 3, Fig. 8c, leads to the lowest utility costs for the acetal.

\section{Origins of the high stability}

The operational stability of organically bridged silica under demanding hydrothermal conditions is unique. For periodic mesoporous materials it has been established that the inclusion of organic bridges is essential for their hydrothermal stability [20]. The solubility of organosilica in water appears to be lower than that of inorganic silica [82].

The increased stability of methylated silica as compared to pure silica has been ascribed to a shielding effect rather than to stabilization of the siloxane bond [9]. Similar as the pendant methyl groups, the organic bridge is not expected to be sufficiently electronegative to further increase the binding energy of the siloxane bonds, although the stability of the organic bridge itself towards hydrolysis is beyond doubt. Alternatively, the increased stability may be attributed to the mechanical properties. The fracture toughness and Young's modulus of organically bridged silica is much higher than that of pure silica [83,84], as studied for low- $k$ dielectric materials [85]. As a result, cracks at the nanoscale are much less likely to propagate through the material, resulting in lower defect concentration. Moreover, the flexibility of the bridge allows the $\mathrm{Si}-\mathrm{O}-\mathrm{Si}$ bonds to relax to their optimal conformation, which has been linked to a lower sensitivity to hydrolytic attack [86,87].

Finally, the minimum hydrothermally stable unit of hybrid silica is linked via six siloxane bonds rather than four as in pure silica. This can result in a lower surface diffusion coefficient. A slower migration than in methylated silica, which densified at $115^{\circ} \mathrm{C}$ within a week in a $2.5 \mathrm{wt} . \%$ water in n-butanol mixture [9], is anticipated.

\section{New manufacturing technologies}

Although less extensively applied than wet chemistry processes in the field of membrane science and technology, vapor-based deposition techniques have been applied successfully. Chemical vapor deposition is a thin-film deposition process following the thermal decomposition of one or more volatile precursors at the surface of a substrate to produce the desired film. One specific example is the counter-diffusion chemical vapor deposition method [88]. The high temperature, $600{ }^{\circ} \mathrm{C}$, and the presence of oxygen used in this method is perfectly suitable for inorganic membranes, but much less so for organically bridged silica membranes. For this latter material, milder conditions are required. Plasma-assisted atomic layer deposition (PA-ALD) and plasma-enhanced chemical vapor deposition (PE-CVD) are solvent-free processes which enable the deposition of hybrid films on large areas and/or thermally sensitive substrates. These thin film deposition methods have a potential for membrane manufacturing as they enable the utilization of polymer supports enabling spiral wound modules [89] for e.g. nanofiltration. However, only a few reports are present in literature on the separation performance of layers developed by means of the above-mentioned "dry chemistry" approaches.

\subsection{Plasma assisted atomic layer deposition (PA-ALD)}

Atomic layer deposition is a self-limiting layer-by-layer thin film deposition technique consisting of successive cycles of surface adsorption and activation of the precursor to develop the deposited layer $[90,91]$. In the PA-ALD, the activation of the adsorbed 

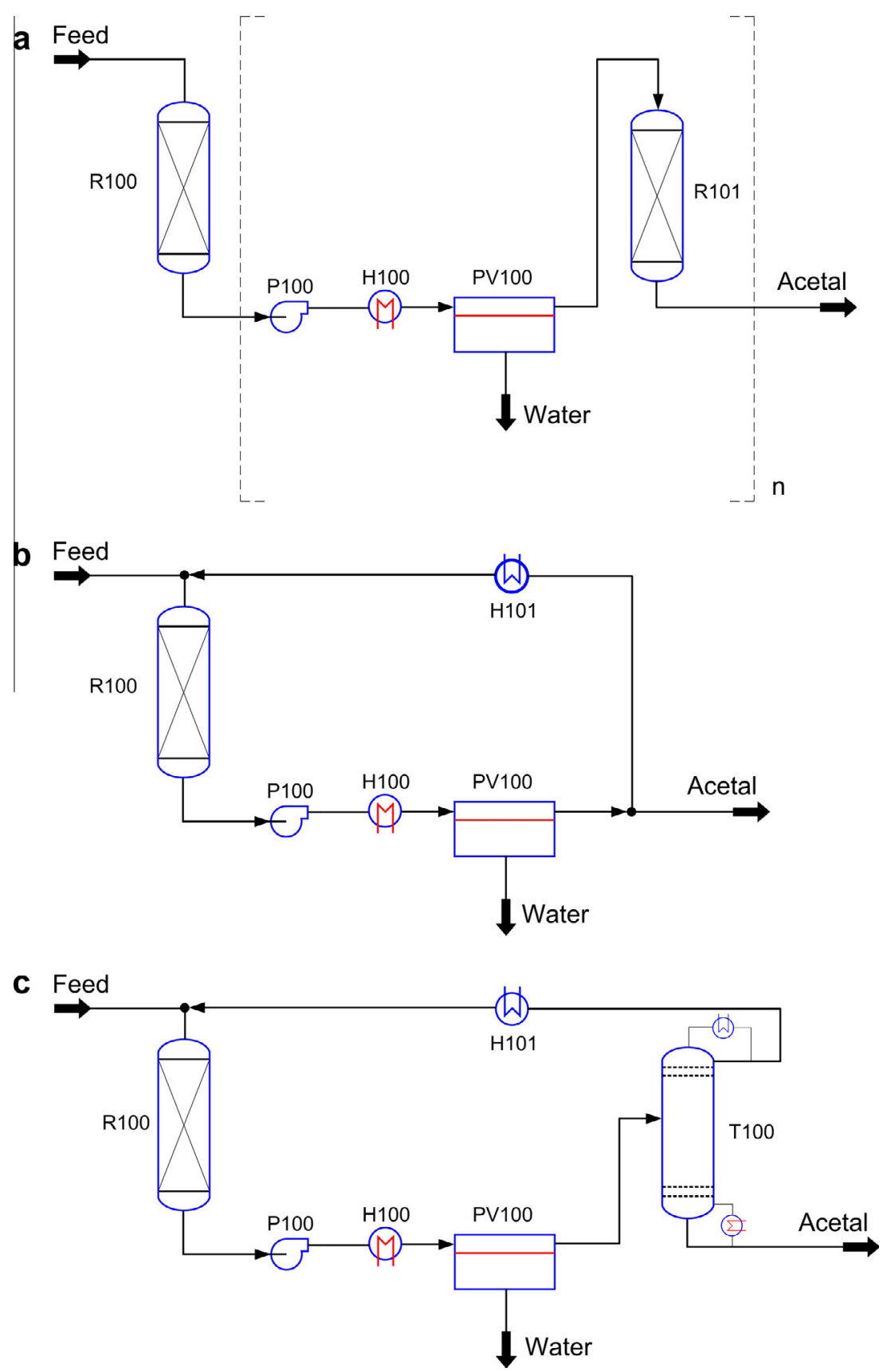

Fig. 8. Flowsheets of membrane based processes, a, b, and c, for configurations 1, 2, and 3, respectively [80].

Table 2

Main results of the developed membrane based processes (bench scale fresh feed rate: $7 \mathrm{~L} / \mathrm{h}$ ) [81].

\begin{tabular}{llll}
\hline Process configuration & Conversion $(\%)$ & Membrane tube length $(\mathrm{m})$ & ${\text { Membrane area }\left(\mathrm{m}^{2}\right)}{\text { Catalyst volume }\left(\mathrm{dm}{ }^{3}\right)}$ \\
\hline (1) Plug flow reactor and pervaporation in series & 70.6 & 2.45 & 1.00 \\
(2) Plug flow reactor and pervaporation in recycle & 71.0 & 0.6 & 1.60 \\
(3) Plug flow reactor, pervaporation, and distillation in recycle & 99.7 & 2 & 0.31 \\
\hline
\end{tabular}

precursor takes place by exposure to a plasma. This way, an ultrathin hybrid organic-inorganic silica membrane layer, $5 \mathrm{~nm}$, was prepared [92] with a $\mathrm{He} / \mathrm{N}_{2}$ selectivity higher than 1000 . To prepare the selective layer, the surface and internal hydroxyl groups of a ceramic-supported mesoporous silica were first converted to trimethylsiloxane groups. By re-exposing the treated support for a very short time to an $\left(\mathrm{Ar}+\mathrm{O}_{2}\right)$ plasma with a Debye length and radical mean free path much larger than the pore size of the mesoporous sub-layer, only the surface trimethylsiloxane groups were converted to silanol groups representing active sites for the adsorption of the BTESE precursor through condensation reactions. The subsequent treatment of the adsorbed BTESE precursor by UV/ ozone exposure removed the organic bridging groups and allowed the development of microporosity. The presence of the ethylene 
Table 3

Comparison of the acetal production costs of three processes taken from [80].

\begin{tabular}{llll}
\hline Process & Base case & Reactive distillation & Pervaporation membrane, configuration 3 \\
\hline Plug flow reactor or reactive distillation conversion & $39 \%$ & $41 \%$ & $43 \%$ \\
Steam at 3.5 bar $\left(\mathrm{kg}_{\text {steam }} / \mathrm{kg}_{\text {acetal }}\right)$ & 1.80 & 3.76 & 1.12 \\
Cooling water $\left(\mathrm{kg}_{\mathrm{H} 2 \mathrm{O}} / \mathrm{kg}_{\text {acetal }}\right)$ & 33.68 & 78.20 & 19.51 \\
Electricity $\left(\mathrm{kW} \mathrm{h} / \mathrm{kg}_{\text {acetal }}\right)$ & 0 & 0 & 0.09 \\
Total capital expenditure $(\mathrm{M} €)$ & 2.01 & 2.85 & 3.76 \\
Total utility costs $(\mathrm{M} € / \mathrm{y})$ & 3.78 & 8.50 & 2.53 \\
Total utility costs $(€ / \mathrm{L})$ & 0.07 & 0.14 & 0.04 \\
Total raw material cost $(€ / \mathrm{L})$ & 0.72 & 0.72 & 0.72 \\
Total production $\operatorname{costs}(€ / \mathrm{L})$ & 0.79 & 0.86 & 0.76 \\
\hline
\end{tabular}

bridging group in the as-deposited layer was confirmed by electron energy-loss spectroscopy. A deposition rate close to zero was obtained when using organosilicon precursors with organic chain-terminating groups. This was ascribed to the formation of terminating alkyl groups at the external surface of the mesoporous silica sub-layer which passivate the surface against further ALD deposition cycles. Even though ethylene bridging groups were deliberately removed in via UV/ozone exposition to create the microporosity, this work showed that dense and ultrathin BTESEderived hybrid silica films can be deposited using the PA-ALD technique.

\subsection{Plasma enhanced chemical vapor deposition (PECVD)}

The generation of a plasma, i.e. the development of reactivity in the gas phase through the application of an electric field, allows lowering the substrate temperature typical of CVD processes as the radicals are produced in the plasma phase [93]. This technique has been successfully applied for silica type membranes [94]. Further, organic groups can remain in place under these conditions as well, as has been demonstrated for polydimethylsiloxane-like membranes without organic bridging moieties [95,96]. One of the preferred precursors is hexamethyldisiloxane [97,98]. The precursor selection has a strong influence on the mechanical properties of silica based layers deposited by means of atmospheric plasma CVD. BTESE-derived organosilica films [99] show a higher Young's modulus and adhesion energy as compared to the films prepared from TEOS and tetramethylcyclotetrasiloxane (TMCTS). The presence of ethylene bridging groups was identified by means of infrared spectroscopy [99].

More recently, the successful deposition of a permselective BTESE-derived organosilica membrane on a polyamide-imide substrate by means of expanding thermal plasma CVD (ETP-CVD), a remote PECVD method, was reported [63,100]. One of the advantages of ETP-CVD compared to conventional rf-PECVD is the suppression of electron impact-induced dissociation reactions. This can be ascribed to the low electron temperature $(<0.3 \mathrm{eV})$ in the downstream region, where the plasma expands [101]. As a consequence, the dissociation of the organosilicon precursor into film depositing radicals is initiated by charge exchange-dissociative recombination reactions between the argon ions and electrons emanating in the downstream region from the plasma source [102]. As such the film composition, density and chemical structure can be tuned by adjusting the BTESE- $\mathrm{Ar}^{+}$ratio $\left(\Phi_{\mathrm{BTESE}} / \Phi_{\mathrm{Ar}+}\right)$ which enabled to control fragmentation of the ethylene bridge. The $\Phi_{\mathrm{BTESE}} / \Phi_{\mathrm{Ar}+}$ ratio also affects the pervaporation performance in the dehydration of a water/n-butanol ( $5 \mathrm{wt} . \% / 95 \mathrm{wt} . \%$ ) mixture as shown in Table 4.

The water concentration in the permeate, Table 4 , is about $18 \mathrm{wt} . \%$ for the pristine polymer. Coating the porous polymeric substrate with a $200 \mathrm{~nm}$ thick top layer increases the water concentration in the permeate up to $98 \mathrm{wt} . \%$. The plasma deposited top layer is highly selective for the transport of water over butanol. At higher values of the $\Phi_{\mathrm{BTESE}} / \Phi_{\mathrm{Ar}+}$ ratio the layer thickness increases. At the same time the water concentration in the permeate decreases from $98 \mathrm{wt} . \%$ to $95 \mathrm{wt} . \%$ and the water flux increases from 1.15 to $2.24 \mathrm{~kg} \mathrm{~m}^{-2} \mathrm{~h}^{-1}$. These effects can be largely ascribed to a reduced density.

\section{Outlook}

\subsection{New supports}

The membranes described above are often deposited in first instance on a flat ceramic discs [51]. This geometry is very suitable for fundamental research, but is unlikely to be suitable for scaling up. A tubular geometry is more appropriate in this case. A layer deposited on the outside of a ceramic tube offers mechanical resistance and easy observation [21]. One possibility to decrease costs is to increase the surface area that can be coated in one single step. This can be achieved through the use of multichannel supports. These are commonly used in filtration applications but have as yet found limited applications for molecular separations such as pervaporation [103]. An additional positive effect is the increased packing density $\left(\mathrm{m}^{2} / \mathrm{m}^{3}\right)$, or membrane surface area per module volume unit. Pressure drops in the support structure may become limiting though.

A completely different approach is applying spiral-wound membrane modules [89]. This requires a technology to deposit hybrid silica onto a flat polymeric support that can be rolled into a spiral-wound module. Recently, major steps have been made into this direction using both sol-gel and ETP-CVD approaches [104]. Such a support system is especially relevant for nanofiltration applications. For a polymeric support generally lower calcination temperatures must by applied. For pervaporation applications and for ceramic supported membranes, it has been shown that this results in a decrease in separation selectivity [59]. The influence of the support on the final membrane performance has not been studied yet. Effective means to overcome this potential disadvantage are essential to come to a profitable membrane behavior. One of the options is a preparation method which does not require a calcination step. The first experiences with ETP-CVD to apply hybrid silica layers on a polymeric support indicate that this is a promising method for this purpose [63]. A recently proposed alternatively, is an $\mathrm{HCl}$ assisted post treatment of a sol-gel membrane at $75^{\circ} \mathrm{C}[60]$.

\subsection{New processes}

The great freedom in organic bridges and terminating groups opens doors to many applications, as tuning of pore size and affinity is possible. The most widely studied application to date is that of pervaporation. However, tests have only been carried out for dehydrating fairly well-known systems. Lesser known 
Table 4

The water contact angle, water flux $\left(J_{\mathrm{H} 2 \mathrm{O}}\right)$, and water concentration in the permeate $\left(W_{\mathrm{p}}\right)$ after 4 days of continuous membrane operation in $95 / 5$ wt.\% $\mathrm{n}$-butanol/water pervaporation $\left(95^{\circ} \mathrm{C}\right)[63]$.

\begin{tabular}{|c|c|c|c|c|c|c|}
\hline Membrane & $\Phi_{\mathrm{BTESE}} / \Phi_{\mathrm{Ar}+}$ & $\begin{array}{l}\text { Density of the top layer } \\
\mathrm{g} / \mathrm{cm}^{3}\end{array}$ & $\begin{array}{l}\text { Layer thickness } \\
\mathrm{Nm}\end{array}$ & $\begin{array}{l}\text { Water contact angle } \\
\circ\end{array}$ & $\begin{array}{l}J_{\mathrm{H} 2 \mathrm{O}} \\
\mathrm{kg} \mathrm{m}^{-2} \mathrm{~h}^{-1}\end{array}$ & $\begin{array}{l}\text { Permeate purity } \\
\text { wt.\% }\end{array}$ \\
\hline $\mathrm{PAI}^{\mathrm{a}}$ & - & - & - & 64 & 4.0 & 17.6 \\
\hline 1 & 0.55 & 1.31 & 200 & 82 & 1.15 & 98.3 \\
\hline 2 & 1.04 & 1.17 & 325 & 78 & 1.77 & 98.4 \\
\hline 3 & 1.85 & 0.88 & 400 & 76 & 2.24 & 95.3 \\
\hline
\end{tabular}

${ }^{\text {a }}$ PAI refers to the pristine polyamide-imide support

multicomponent systems may lead to the first markets. The case study for the acetal production has shown that a small pervaporation unit can relieve the burden on the distillation column significantly. Similar industrial processes in which components with various volatilities and azeotropes coexist deserve to be analyzed and investigated [5,6]. Also, the integration of reaction and membrane separation is a promising direction. Process analyses [74] have shown clear advantages of membrane processes in esterification reactions, especially for reactions that are thermodynamically hindered in which water is formed as a byproduct. The presence of significant concentrations of the homogeneous catalyst methanesulfonic acid in esterification reactions [74] leads to a very fast decay of the membrane [64]. However, the apparent very low solubility of these hybrid materials under acidic conditions [82] may indicate a route to improve the acid stability.

In process analyses, the effect of the temperature should be studied as well. Esterification reactions tend to be exothermic and an increase in temperature results in a decrease in conversion. For this reason the reaction temperatures are kept fairly low $[66,74]$. However, both reaction kinetics and membrane flux can be increased by using a higher temperature. Several esterification reactions are already operated at temperatures as high as $200^{\circ} \mathrm{C}$ and the hybrid silica membrane can function up to these temperatures for a prolonged period without a negative impact on the stability. This also means that no additional cooling step is needed. Detailed studies need to determine the optimal reaction conditions in such a separation assisted reactor system.

Another type of separation that has been investigated is desalination via reverse osmosis [105]. Reverse osmosis is a widely used technique to produce high purity water [106]. It is unlikely that current commercial polymeric membranes will be replaced with the hybrid membranes described here. Opportunities may be present for operation under more extreme conditions where the increased stability of the hybrid membranes can be fully utilized or when high osmotic pressures have to be overcome. One can think of higher temperatures and higher salt concentrations. This may be especially useful for applications in which the process mixture is already at a high temperature.

Finally, the separation of olefins from paraffins is of interest. Membranes can be used in retrofit options to debottleneck the distillation column [80]. The required separation performance has as yet not been achieved [107].

\subsection{Materials development}

From this review it is clear that in recent years the knowledge around the current class of hybrid organosilica membranes has grown considerably. Still, some important issues have not been addressed or the application demands have not been met. It is clear that the enhanced hydrothermal stability has resulted in a lower thermal stability. Still, the exact conditions of, most notably, temperature and oxygen content under which the hydrocarbon bridge starts to disintegrate have not been determined.

Manufacturing cost reductions can be achieved through modified calcination protocols. This can be related to the feasibility to perform the calcination in the presence of oxygen, air, rather than under inert conditions. Also, the recent development of rapid heating and cooling procedures [108] is likely to result in cost reductions. The correlation between the preparative method and procedure, i.e. sol-gel vs. ETP-CVD, recipe, calcination temperature, the resulting material and membrane, and the long term separation performance is greatly lacking. This could be established with the above cost reducing options in mind.

A recent, novel and promising preparation method for organosilica hybrid membranes is that of interfacial polymerization [109], in which extensive hydrocarbon links are formed between polyhedral oligosilsesquioxanes [110]. More research is required to show that this preparation technique can be as successful as the sol-gel method.

\section{Conclusions}

In this review an overview of the current status of organic-inorganic silica-based molecular membranes has been presented. It was shown that the incorporation of especially alkyl hydrocarbon bridges greatly enhances the applicability of the sol-gel membranes. Furthermore that gas phase deposition methods can be used to make functional hybrid membranes. The main advantage of this membrane system is an exceptionally high stability under especially hydrothermal conditions. Long-term data sets for periods of over a year are available for a number of applications and show the structural integrity of the membranes involved.

By selection of the appropriate precursor the properties of the membranes can be tailored towards specific applications. Till date all process requirements have been met by the pervaporation membranes. For other fields of applications such as gas separation and nanofiltration further development and improvement of the selectivity are still required. This is likely to go hand in hand with support optimization, like architecture and material selection. The flexibility in preparation technology, i.e. sol-gel and expanding thermal plasma CVD technique and possibly interfacial polymerization, offers further options to come to new types of membranes with a different application window. To achieve this, more knowledge is also required on the processes that change the chemical and physical structure of the material during preparation and upon application in various separation conditions.

Together with the recent results and future developments it is likely that the interest in this field will grow in the near future.

\section{Acknowledgements}

This research was supported by the Netherlands Technology Foundation STW and the EOS technology program of the Dutch Ministry of Economic Affairs, administered by Agentschap NL, and by the Institute of Sustainable Process Technology, ISPT.

\section{References}

[1] International Energy Agency, Energy Technology Perspectives; Scenarios \& Strategies to 2050, 2008. 
[2] M. Nomura, T. Bin, S.-I. Nakao, Selective ethanol extraction from fermentation broth using a silicalite membrane, Sep. Purif. Technol. 27 (2002) 59-66.

[3] K.L. Wasewar, V.G. Pangarkar, Intensification of recovery of ethanol from fermentation broth using pervaporation: economical evaluation, Chem. Biochem. Eng. Q 20 (2006) 135-145.

[4] W.J. Koros, Evolving beyond the thermal age of separation processes: membranes can lead the way, AIChE. J. 50 (2005) 2326-2334.

[5] T. Roth, P. Kreis, A. Gorak, Process analysis and optimisation of hybrid processes for the dehydration of ethanol, Chem. Eng. Res. Des. 191 (2013) 1171-1185.

[6] P. Lutze, A. Gorak, Reactive and membrane-assisted distillation: recent developments and perspective, Chem. Eng. Res. Des. (2013). <http:// dx.doi.org/10.1016/j.cherd.2013.07.011>

[7] H.M. van Veen, Y.C. van Delft, C.W.R. Engelen, P.P.A.C. Pex, Dewatering of organics by pervaporation with silica membranes, Sep. Purif. Technol. 22-23 (2001) 361-366

[8] M. Asaeda, J. Yang, Y. Sakou, Porous silica-zirconia (50\%) membranes for pervaporation of iso-propyl alcohol (IPA)/water mixtures, J. Chem. Eng. Jpn. 35 (2002) 365.

[9] J. Campaniello, C.W.R. Engelen, W.G. Haije, P.P.A.C. Pex, J.F. Vente, Long-term pervaporation performance of microporous methylated silica membranes, Chem. Commun. (2004) 834-835.

[10] R.M. de Vos, W.F. Maier, H. Verweij, Hydrophobic silica membranes for gas separation, J. Membr. Sci. 158 (1999) 277-288

[11] B. Will, R.N. Lichtenthaler, Comparision of the separation of mixtures by vapor permeation and by pervaporation using PVA composite membranes. I. Binary alcohol-water systems, J. Membr. Sci. 68 (1992) 119-125.

[12] R. Kreiter, D.P. Wolfs, C.W.R. Engelen, H.M. van Veen, J.F. Vente, Hightemperature pervaporation performance of ceramic-supported polyimide membranes in the dehydration of alcohols, J. Membr. Sci. 319 (2008) 126132.

[13] C. Guizard, A. Bac, M. Barboiu, N. Hovnanian, Hybrid organic-inorganic membranes with specific transport properties. Applications in separation and sensors technologies, Sep. Purif. Technol. 25 (2001) 167-180.

[14] C.J. Brinker, G.W. Scherer, Sol-gel Science - The Physics and Chemistry of Solgel Processing, Academic Press, New York, 1990.

[15] K.J. Shea, D.A. Loy, O. Webster, Arylsilsesquioxane gels and related materials. New hybrids of organic and inorganic networks, J. Am. Chem. Soc. 114 (1992) 6700-6710.

[16] K.J. Shea, D.A. Loy, Bridged polysilsesquioxanes. Molecular-engineered hybrid organic-inorganic materials, Chem. Mater. 13 (2001) 3306-3319.

[17] H.W. Oviatt-Jr, K.J. Shea, J.H. Small, Alkylene-bridged silsesquioxane sol-gel synthesis and xerogel characterization. Molecular requirements for porosity, Chem. Mater. 5 (1993) 943-950.

[18] D.A. Loy, G.M. Jamison, B.M. Baugher, E.M. Russick, R.A. Assink, S. Prabaker, K.J. Shea, Alkylene-bridged polysilsesquioxane aerogels: highly porous hybrid organic-inorganic materials, J. Non-Cryst. Solids 186 (1995) 44-53.

[19] Y. Lu, H. Fan, N. Doke, D.A. Loy, R.A. Assink, D.A. LaVan, C.J. Brinker, Evaporation-induced self-assembly of hybrid bridged silsesquioxane film and particulate mesophases with integral organic functionality, J. Am. Chem. Soc. 122 (2000) 5258-5261.

[20] G. Smeulders, V. Meynen, A. Silvestre-Albero, K. Houthoofd, M. Mertens, J. Silvestre-Albero, J.A. Martens, P. Cool, The impact of framework organic functional groups on the hydrophobicity and overall stability of mesoporous silica materials, Mater. Chem. Phys. 132 (2012) 1077-1088.

[21] H.L. Castricum, A. Sah, R. Kreiter, D.H.A. Blank, J.F. Vente, J.E. ten Elshof, Hybrid ceramic nanosieves: stabilizing nanopores with organic links, Chem. Commun. (2008) 1103-1105.

[22] R.S.A. de Lange, J.H.A. Hekkink, K. Keizer, A.J. Burggraaf, Formation and characterization of supported microporous ceramic membranes prepared by sol-gel modification techniques, J. Membr. Sci. 99 (1995) 57-75.

[23] C.J. Brinker, N.K. Raman, M.N. Logan, R. Sehgal, R.A. Assink, D.-W. Hua, T.L. Ward, Structure-property relations in thin films and membranes, J. Sol-Gel Sci. Technol. 4 (1995) 117-133.

[24] M. Asaeda, S. Yamasaki, Separation of inorganic/organic gas mixtures by porous silica membranes, Sep. Purif. Technol. 25 (2001) 151-159.

[25] B.C. Bonekamp, R. Kreiter, J.F. Vente, Sol-gel approaches in the synthesis of membrane materials for nanofiltration and pervaporation, in: P. Innocenzi, Y.L. Zub, V.G. Kessler (Eds.), Sol-Gel Methods for Materials Processing Focusing on Materials for Pollution Control, Water Purification, and Soil Remediation, Springer, Netherlands, 2008, pp. 47-65.

[26] J.F. Vente, H.M. van Veen, P.P.A.C. Pex, Microporous sol-gel membranes for molecular separations, Ann. Chim. Sci. Mater. 32 (2007) 231-244.

[27] C.J. Brinker, R. Sehgal, S.L. Hietala, R. Deshpande, D.M. Smith, D.A. Loy, C.S. Ashley, Sol-gel strategies for controlled porosity inorganic materials, J. Membr. Sci. 94 (1994) 85-102.

[28] M. Asaeda, M. Kanezashi, T. Yoshioka, T. Tsuru, Gas permeation characteristics and stability of composite silica-metal oxide membranes, Mater. Res. Soc. Symp. Proc. 752 (2003) 213-218.

[29] S. Smart, J.F. Vente, J.C. Diniz Da Costa, High temperature $\mathrm{H}_{2} / \mathrm{CO}_{2}$ separation using cobalt oxide silica membranes, Int. J. Hydrogen Energy 37 (2012) $12700-12707$.

[30] M. Asaeda, M. Ishida, Y. Tasaka, Pervaporation characteristics of silicazirconia membranes for separation of aqueous organic solutions, Sep. Sci. Technol. 40 (2006) 239-254.
[31] V. Boffa, J.E. ten Elshof, A.I. Petukhov, D.H.A. Blank, Microporous niobia-silica membrane with very low $\mathrm{CO}_{2}$ permeability, Chem. Sus. Chem. 1 (2008) 437443.

[32] V. Boffa, D.H.A. Blank, J.E. ten Elshof, Hydrothermal stability of microporous silica and niobia-silica membranes, J. Membr. Sci. 319 (2008) 256-263.

[33] J. Sekulic, J.E. ten Elshof, D.H.A. Blank, A microporous titania membrane for nanofiltration and pervaporation, Adv. Mater. 16 (2004) 1546-1550.

[34] J. Sekulic, J.E. ten Elshof, D.H.A. Blank, Selective pervaporation of water through a nonselective microporous titania membrane by a dynamically induced molecular sieving mechanism, Langmuir 21 (2005) 508-510.

[35] R. Kreiter, M.D.A. Rietkerk, B.C. Bonekamp, H.M. van Veen, V.G. Kessler, J.F. Vente, Sol-gel routes towards microporous titania and zirconia membranes, J. Sol-Gel Sci. Technol. 48 (2008) 203-211.

[36] G.I. Spijksma, C. Huiskes, N.E. Benes, H. Kruidhof, D.H.A. Blank, V.G. Kessler, H.J.M. Bouwmeester, Microporous zirconia-titania composite membranes derived from diethanolamine-modified precursors, Adv. Mater. 18 (2006) 2165-2168.

[37] T. van Gestel, D. Sebold, F. Hauler, W.A. Meulenberg, H.P. Buchkremer, Potentialities of microporous membranes for $\mathrm{H}_{2} / \mathrm{CO}_{2}$ separation in future fossil fuel power plants: evaluation of $\mathrm{SiO}_{2}, \mathrm{ZrO}_{2}, \mathrm{Y}_{2} \mathrm{O}_{3}-\mathrm{ZrO}_{2}$ and $\mathrm{TiO}_{2}-\mathrm{ZrO}_{2}$ sol-gel membranes, J. Membr. Sci. 359 (2010) 64-79.

[38] A.F.M. Leenaars, K. Keizer, A.J. Burggraaf, The preparation and characterization of alumina membranes with ultra-fine pores, Part 1, Microstructural investigations on non supported membranes, J. Mater. Sci. 19 (1984) 1077.

[39] B.C. Bonekamp, A. van Horssen, L.A. Correia, J.F. Vente, W.G. Haije, Macroporous support coatings for molecular separation membranes having a minimum defect density, J. Membr. Sci. 278 (2006) 349-356.

[40] R.M. de Vos, H. Verweij, High-selectivity, high-flux silica membranes for gas separation, Science 279 (1998) 1710-1711.

[41] G. Li, M. Kanezashi, T. Tsuru, Preparation of organic-inorganic hybrid silica membranes using organoalkoxysilanes: the effect of pendant groups, J. Membr. Sci. 379 (2011) 287-295.

[42] Q. Wei, F. Wang, Z.R. Nie, C.L. Song, Y.L. Wang, Q.Y. Li, Highly hydrothermally stable microporous silica membranes for hydrogen separation, J. Phys. Chem. B 112 (2008) 9354-9359.

[43] Q. Wei, Y.L. Wang, Z.R. Nie, C.X. Yu, Q.Y. Li, J.X. Zou, C.J. Li, Facile synthesis of hydrophobic microporous silica membranes and their resistance to humid atmosphere, Micropor. Mesopor. Mater. 111 (2008) 97-103.

[44] G. Xomeritakis, C.Y. Tsai, C.J. Brinker, Microporous sol-gel derived aminosilicate membrane for enhanced carbon dioxide separation, Sep. Purif. Technol. 42 (2005) 249-257.

[45] G. Xomeritakis, C.Y. Tsai, Y.B. Jiang, C.J. Brinker, Tubular ceramic-supported sol-gel silica-based membranes for flue gas carbon dioxide capture and sequestration, J. Membr. Sci. 341 (2009) 30-36.

[46] H.L. Castricum, G.G. Paradis, M.C. Mittelmeijer-Hazeleger, R. Kreiter, J.F. Vente, J.E. ten Elshof, Tailoring the separation behavior of hybrid organosilica membranes by adjusting the structure of the organic bridging group, Adv. Funct. Mater. 21 (2011) 2319-2329.

[47] R. Kreiter, M.D.A. Rietkerk, H.L. Castricum, H.M. van Veen, J.E. ten Elshof, J.F. Vente, Stable hybrid silica nanosieve membranes for the dehydration of lower alcohols, ChemSusChem 2 (2009) 158-160.

[48] H. Qi, Preparation of composite microporous silica membranes using TEOS and 1,2-bis(triethoxysilyl)ethane as precursors for gas separation, Chin. J. Chem. Eng. 19 (2011) 404-409.

[49] G.G. Paradis, D.P. Shanahan, R. Kreiter, H.M. van Veen, H.L. Castricum, A. Nijmeijer, J.F. Vente, From hydrophilic to hydrophobic HybSi ${ }^{\circledR}$ membranes: a change of affinity and applicability, J. Membr. Sci. 428 (2013) 157-162.

[50] G.G. Paradis, R. Kreiter, M.M.A. van Tuel, A. Nijmeijer, J.F. Vente, Aminofunctionalized microporous hybrid silica membranes, J. Mater. Chem. 22 (2012) 7258-7264.

[51] H. Qi, J. Han, N. Xu, H.J.M. Bouwmeester, Inorganic microporous membranes with high hydrothermal stability for the separation of carbon dioxide, ChemSusChem 3 (2010) 1375-1378.

[52] H. Qi, J. Han, N. Xu, Effect of calcination temperature on carbon dioxide separation properties of a novel microporous hybrid silica membrane, J. Membr. Sci. 382 (2011) 231-237.

[53] Y. Lu, G. Cao, R.P. Kale, S. Prabakar, G.P. Lopez, C.J. Brinker, Microporous silica prepared by organic templating: relationship between the molecular template and pore structure, Chem. Mater. 11 (1999) 1223-1229.

[54] N.K. Raman, C.J. Brinker, Organic "template" approach to molecular sieving silica membranes, J. Membr. Sci. 105 (1995) 273-279.

[55] C.Y. Tsai, S.Y. Tam, Y. Lu, C.J. Brinker, Dual-layer asymmetric microporous silica membranes, J. Membr. Sci. 169 (2000) 255-268.

[56] H.L. Castricum, A. Sah, J. Geenevasen, R. Kreiter, D.H.A. Blank, J.F. Vente, J.E. ten Elshof, Structure of hybrid organic-inorganic sols for the preparation of hydrothermally stable membranes, J. Sol-Gel Sci. Technol. 48 (2008) 11-17.

[57] H.L. Castricum, A. Sah, R. Kreiter, D.H.A. Blank, J.F. Vente, J.E. ten Elshof, Hydrothermally stable molecular separation membranes from organically linked silica, J. Mater. Chem. 18 (2008) 2150-2158.

[58] S.R. Aragon, R. Pecora, Theory of dynamic light scattering from polydisperse systems, J. Chem. Phys. 64 (1976) 2395-2404.

[59] J. Wang, M. Kanezashi, T. Yoshioka, T. Tsuru, Effect of calcination temperature on the PV dehydration performance of alcohol aqueous solutions through BTESE-derived silica membranes, J. Membr. Sci. 415-416 (2012) 810-815. 
[60] J. Wang, G. Gong, M. Kanezashi, T. Yoshioka, K. Ito, T. Tsuru, Pore-size tuning of highly selective organic-inorganic hybrid silica membranes by solid-phase post-treatment at low temperature, Chem. Lett. 41 (12) (2012) 1663-1665.

[61] M. Kanezashi, K. Yada, T. Yoshioka, T. Tsuru, Organic-inorganic hybrid silica membranes with controlled silica network size: preparation and gas permeation characteristics, J. Membr. Sci. 348 (2010) 310-318.

[62] H. Qi, J. Han, X. Jiang, W. Xing, Y. Fan, Preparation and hydrothermal stability of organic-inorganic hybrid silica membrane, Wuji Cailiao Xuebao/J. Inorg. Mater. 25 (2010) 758-764

[63] P.H.T. Ngamou, J.P. Overbeek, R. Kreiter, H.M. van Veen, J.F. Vente, I.M. Wienk, P. Cuperus, M. Creatore, Plasma-deposited hybrid silica membranes with controlled retention of organic bridges, J. Mater. Chem. A 1 (2013) 55675576.

[64] H.M. van Veen, M.D. Rietkerk, D.P. Shanahan, M.M.A. van Tuel, R. Kreiter, H.L Castricum, J.E. ten Elshof, J.F. Vente, Pushing membrane stability boundaries with HybSi ${ }^{\circledR}$ pervaporation membranes, J. Membr. Sci. 380 (2011) 124-131.

[65] H.L. Castricum, A. Sah, M.C. Mittelmeijer-Hazeleger, C. Huiskes, J.E. ten Elshof, Microporous structure and enhanced hydrophobicity in methylated $\mathrm{SiO}_{2}$ for molecular separation, J. Mater. Chem. 17 (2007) 1509-1517.

[66] I. Agirre, M.B. Guemez, H.M. van Veen, A. Motelica, J.F. Vente, P.L. Arias, Acetalization reaction of ethanol with butyraldehyde coupled with pervaporation. Semi-batch pervaporation studies and resistance of $\mathrm{HybSi}^{\circledR}$ membranes to catalyst impacts, J. Membr. Sci. 371 (2011) 179-188.

[67] M. Asaeda, M. Ishida, T. Waki, Pervaporation of aqueous organic acid solutions by porous ceramic membranes, J. Chem. Eng. Jpn. 38 (2005) 336343.

[68] T. Tsuru, T. Shibata, J. Wang, H.R. Lee, M. Kanezashi, T. Yoshioka, Pervaporation of acetic acid aqueous solutions by organosilica membranes, J. Membr. Sci. 421-422 (2012) 25-31.

[69] H.L. Castricum, R. Kreiter, H.M. van Veen, D.H.A. Blank, J.F. Vente, J.E. ten Elshof, High-performance hybrid pervaporation membranes with superior hydrothermal and acid-stability, J. Membr. Sci. 324 (2008) 111-118.

[70] R. Kreiter, H.M. van Veen, M.D.A. Rietkerk, C.W.R. Engelen, H.L. Castricum, J.E ten Elshof, J.F. Vente, Peformance of a new hybrid membrane in high temperature pervaporation, Tokyo, 2008.

[71] K.-S. Chang, T. Yoshioka, M. Kanezashi, T. Tsuru, K.-L. Tung, Molecular simulation of micro-structures and gas diffusion behavior of organicinorganic hybrid amorphous silica membranes, J. Membr. Sci. 381 (2011) 90-101.

[72] H. Qi, H. Chen, L. Li, G. Zhu, N. Xu, Effect of Nb content on hydrothermal stability of a novel ethylene-bridged silsesquioxane molecular sieving membrane for $\mathrm{H}_{2} / \mathrm{CO}_{2}$ separation, J. Membr. Sci. 421-422 (2012) 190-200.

[73] R.M. de Vos, H. Verweij, Improved performance of silica membranes for gas separation, J. Membr. Sci. 143 (1998) 37-51.

[74] J.T.F. Keurentjes, G.H.R. Janssen, J.J. Gorissen, The esterification of tartaric acid with ethanol: kinetics and shifting the equilibrium by means of pervaporation, Chem. Eng. Sci. 49 (1994) 4681-4689.

[75] V.M.T.M. Silva, C.S.M. Pereira, A.E. Rodrigues, PermSMBR-a new hybrid technology: application on green solvent and biofuel production, AIChE. J. 57 (2011) 1840-1851.

[76] V.M.T.M. Silva, A.E. Rodrigues, Novel process for diethylacetal synthesis, AIChE. J. 51 (2011) 2752-2768.

[77] N.S. Graça, L.S. Pais, V.M.T.M. Silva, A.E. Rodrigues, Dynamic study of the synthesis of 1,1-dibutoxyethane in a fixed-bed adsorptive reactor, Sep. Sci. Technol. 46 (2011) 631-640.

[78] I. Agirre, V.L. Barrio, M.B. Guemez, J. Cambra, P.L. Arias, Bioenergy II: the development of a reactive distillation process for the production of 1,1 diethoxy butane from bioalcohol: kinetic study and simulation model, Int. J. Chem. React. Eng. 8 (2010) A86.

[79] I. Agirre, V.L. Barrio, M.B. Guemez, J. Cambra, P.L. Arias, Catalytic reactive distillation process development for 1,1 diethoxy butane production from renewable sources, Bioresour. Technol. 102 (2011) 1289-1297.

[80] I. Agirre, M.B. Guemez, A. Motelica, H.M. van Veen, J.F. Vente, P.L. Arias, A techno-economic comparison of the various processes for the production of 1,1 diethoxy butane, J. Chem. Technol. Biotechnol. 87 (2012) 943-954.

[81] I. Agirre, M.B. Guemez, A. Motelica, H.M. van Veen, J.F. Vente, P.L. Arias, The conceptual design of a continuous pervaporation membrane reactor for the production of 1,1-diethoxy butane, AIChE. J. 58 (2011) 1862-1868.

[82] H.L. Castricum, G.G. Paradis, M.C. Mittelmeijer-Hazeleger, W. Bras, G. Eeckhaut, J.F. Vente, G. Rothenberger, J.E. ten Elshof, Tuning the nanopore structure and separation behavior of hybrid organosilica membranes, J Mater. Chem. A (2013), (submitted for publication)

[83] G. Dubois, W. Volksen, T. Magbitang, R.D. Miller, D.M. Gage, R.H. Dauskardt Molecular network reinforcement of sol-gel glasses, Adv. Mater. 19 (2007) 3989-3994.

[84] G. Dubois, W. Volksen, T. Magbitang, M.H. Sherwood, R.D. Miller, D.M. Gage, R.H. Dauskardt, Superior mechanical properties of dense and porous organic/ inorganic hybrid thin films, J. Sol-Gel Sci. Technol. 48 (2008) 187-193.
[85] W. Volksen, R.D. Miller, G. Dubois, Low dielectric constant materials, Chem. Rev. 110 (2009) 56-110.

[86] T.A. Michalske, S.W. Freiman, A molecular interpretation of stress corrosion in silica, Nature 295 (1982) 511-512.

[87] T.A. Michalske, B.C. Bunker, A chemical kinetics model for glass fracture, J. Am. Ceram. Soc. 76 (1993) 2613-2618.

[88] M. Nomura, K. Ono, S. Gopalakrishnan, T. Sugawara, S.-I. Nakao, Preparation of a stable silica membrane by a counter diffusion chemical vapor deposition method, J. Membr. Sci. 251 (2005) 151-158.

[89] F. Li, W. Meindersma, A.B. de Haan, T. Reith, Optimization of commercial net spacers in spiral wound membrane modules, J. Membr. Sci. 208 (2002) 289302.

[90] S.M. George, Atomic layer deposition: an overview, Chem. Rev. 110 (2009) $111-131$

[91] H.B. Profijt, S.E. Potts, d.S. van, W.M.M. Kessels, Plasma-assisted atomic layer deposition: basics, opportunities, and challenges, J. Vac. Sci. Technol., A 29 (2011). 050801-1-050801/26.

[92] Y.B. Jiang, G. Xomeritakis, Z. Chen, D. Dunphy, D.J. Kissel, J.L. Cecchi, C.J. Brinker, Sub-10 nm thick microporous membranes made by plasma-defined atomic layer deposition of a bridged silsesquioxane precursor, J. Am. Chem. Soc. 129 (2007) 15446-15447.

[93] K.L. Choy, Chemical vapor deposition of coatings, Prog. Mater. Sci. 48 (2003) $57-170$.

[94] T. Tsuru, H. Shigemoto, M. Kanezashi, T. Yoshioka, 2-Step plasma-enhanced CVD for low-temperature fabrication of silica membranes with high gasseparation performance, Chem. Commun. 47 (2011) 8070-8072.

[95] S. Roualdes, J. Sanchez, J. Durand, Gas diffusion and sorption properties of polysiloxane membranes prepared by PECVD, J. Membr. Sci. 198 (2002) 299310.

[96] H. Matsuyama, A. Kariya, M. Teramoto, Effect of siloxane chain lengths of monomers on characteristics of pervaporation membranes prepared by plasma polymerization, J. Appl. Polym. Sci. 51 (1994) 689-693.

[97] Y.Y. Ji, H.K. Chang, Y.C. Hong, S.H. Lee, Formation of hydrophobic and waterrepellent surface on polyester fibers using $\mathrm{Ar} /$ hexamethyldisiloxane plasma at atmospheric pressure, Jpn. J. Appl. Phys. 47 (2008) 4687-4691.

[98] A. Dabrowski, M. Barczak, N.V. Stolyarchuk, I.V. Melnyk, Y. Zub, Bridged polysilsesquioxane xerogels functionalizated by amine- and thiol- groups: synthesis, structure, adsorption properties, Adsorption 11 (2005) 501-517.

[99] L. Cui, A.N. Ranade, M.A. Matos, L.S. Pingree, T.J. Frot, G. Dubois, R.H. Dauskardt, Atmospheric plasma deposited dense silica coatings on plastics, ACS Appl. Mater. Interfaces 4 (2012) 6587-6598.

[100] P.H.T. Ngamou, J.P. Overbeek, H.M. van Veen, J.F. Vente, F.P. Cuperus, M. Creatore, On the enhancement of pervaporation properties of plasmadeposited hybrid silica membranes, RSC Adv. (2013).

[101] M.C.M. van de Sanden, R.J. Severens, W.M.M. Kessels, R.F.G. Meulenbroeks, D.C. Schram, Plasma chemistry aspects of a-Si:H deposition using an expanding thermal plasma, J. Appl. Phys. 84 (1998) 2426-2435.

[102] M. Creatore, Y. Barrell, J. Benedikt, M.C.M. van de Sanden, On the hexamethyldisiloxane dissociation paths in a remote Ar-fed expanding thermal plasma, Plasma Sources Sci. Technol. 15 (2006) 421-431.

[103] M. Weyd, H. Richter, J.T. Kuehnert, I. Voigt, E. Tusel, H. Brueschke, Efficient dehydration of ethanol by zeolite membranes in four-channel geometry, Chem. Ing. Tech. 82 (2010) 1257-1260.

[104] F.P. Cuperus, I.M. Wienk, J.P. Overbeek, H.M. van Veen, J.F. Vente, P.H.T. Ngamou, M. Creatore, Towards a truly hybrid membrane for organic solvent nanofiltration, 2013.

[105] R. Xu, J. Wang, M. Kanezashi, T. Yoshioka, T. Tsuru, Development of robust organosilica membranes for reverse osmosis, Langmuir 27 (2011) 1399613999.

[106] K.S. Spiegler, L. Kedem, Thermodynamics of hyperfiltration (reverse osmosis): criteria for efficient membranes, Desalination 1 (1966) 311-326.

[107] M. Kanezashi, M. Kawano, T. Yoshioka, T. Tsuru, Organic-inorganic hybrid silica membranes with controlled silica network size for propylene/propane separation, Ind. Eng. Chem. Res. 51 (2012) 949-958

[108] E.J. Kappert, A. Nijmeijer, N.E. Benes, Expeditious calcination of inorganic membranes by an instant temperature increment, Micropor. Mesopor. Mater. 151 (2012) 211-215.

[109] M. Dalwani, J. Zheng, M. Hempenius, M.J.T. Raaijmakers, C.M. Doherty, A.J. Hill, M. Wessling, N.E. Benes, Ultra-thin hybrid polyhedral silsesquioxanepolyamide films with potentially unlimited 2D dimensions, J. Mater. Chem. 22 (2012) 14835-14838.

[110] E.G. Shockey, A.G. Bolf, P.F. Jones, J.J. Schwab, K.P. Chaffee, T.S. Haddad, J.D. Lichtenhan, Functionalized polyhedral oligosilsesquioxane (POSS) macromers: new graftable POSS hydride, POSS olefin, POSS epoxy, and POSS chlorosilane macromers and POSS-siloxane triblocks, Appl. Organomet. Chem. 13 (1999) 311-327. 


\section{ECN}

Westerduinweg 3

1755 LE Petten

P.O. Box 1

The Netherlands

\section{LG Petten}

The Netherlands

$T+31885154949$

$F+31885158338$

info@ecn.nl

www.ecn.nl 